\title{
1 The specificity of sperm-mediated paternal effects in threespined sticklebacks
}

3 Eunice Chen $^{1}$, Christian Zielinski ${ }^{1}$, Jack Deno ${ }^{1}$, Raiza Singh ${ }^{1}$, Alison M Bell ${ }^{1,2,3}$, Jennifer K

4 Hellmann ${ }^{1 \dagger}$

5

$6{ }^{1}$ Department of Evolution, Ecology and Behavior, School of Integrative Biology, University

7 of Illinois Urbana-Champaign, Urbana, Illinois, USA, 61801

$8{ }^{2}$ Carl R. Woese Institute for Genomic Biology, University of Illinois Urbana-Champaign,

9 Urbana, Illinois, USA, 61801

$10{ }^{3}$ Program in Ecology, Evolution and Conservation, University of Illinois Urbana-Champaign,

11 Urbana, Illinois, USA, 61801,

12

$13{ }^{\dagger}$ Corresponding author: Jennifer Hellmann, 505 S Goodwin Ave, Urbana IL 61801,

14 hellmann@illinois.edu 


\section{Abstract}

16 Parental effects can help offspring cope with challenging environments, but whether

17 these effects are unique to specific environmental conditions is largely unknown. Parental

18 effects may evolve via a core pathway that generally prepares offspring for risky

19 environments or could be stimuli-specific, with offspring developing phenotypes that are

20 tailored to specific environmental challenges. We exposed threespined sticklebacks

21 (Gasterosteus aculeatus) fathers to a potentially threatening stimulus (net) versus native

22 predator (sculpin). Offspring of sculpin-exposed fathers were more responsive (greater

23 change in activity) to a simulated predator attack, while offspring of net-exposed fathers were

24 less responsive (lower plasma cortisol and fewer antipredator behaviors). To evaluate

25 offspring response to native and non-native stimuli, we sequentially exposed offspring of net-

26 exposed, sculpin-exposed or control fathers to a net, native sculpin model, or non-native trout

27 model. Paternal treatment did not influence offspring response to stimuli; instead, offspring

28 were more responsive to the native sculpin predator compared to nets or non-native trout

29 predator. Collectively, we demonstrate that sperm-mediated paternal effects in response to

30 different, potentially stressful stimuli result in distinct offspring phenotypes. This specificity

31 may be key to understanding the evolution of adaptive parental effects and how parents prime

32 offspring for encountering both evolved and novel environmental stimuli.

35 Key words: phenotypic plasticity, Gasterosteus aculeatus, nongenetic inheritance, predation

36 risk, transgenerational plasticity, predator recognition 


\section{Background}

38 Transgenerational plasticity (environmental parental effects) occurs when the

39 environment experienced by one generation influences the phenotypes of future generations.

40 Transgenerational plasticity may have evolved as a mechanism to help organisms to cope

41 with changing environments and can have adaptive consequences for offspring (reviewed in

42 [1-3]). Despite growing evidence for parental effects in response to environmental challenges

43 such as predation risk, the ways in which parental effects prime offspring for specific

44 environmental conditions is largely unknown.

45 On one hand, there may one conserved pathway by which the parental environment

46 alters offspring phenotypes, such that different environmental conditions experienced by

47 parents (e.g., low food availability, drought, predation) have the same intergenerational

48 consequences: parents produce offspring with traits that help them cope with low quality

49 environments (e.g., dispersal, altered stress responsivity). For example, female bluebirds

50 adjust sex-biased laying order to shift offspring dispersal in response to low nest cavity

51 abundance, cold temperature, or reduced kin proximity [4]. This generalized response could

52 be adaptive by allowing parents to convey a message of environmental risk, even if they lack

53 certain information about environmental cues (e.g. do not have to evaluate if high predation

54 is due to sit-and-wait predators or active foragers) or encounter a novel stressor (e.g., a non-

55 native predator). Alternatively, it could arise because low quality environments generally

56 increase parental stress and/or reduce body condition [5-7]. On the other hand, parental

57 effects may be highly specific, such that different parental conditions have very different

58 intergenerational effects. For example, maternal social instability stress in mice increased

59 anxiety predominantly in female offspring, while restraint stress reduced anxiety in offspring

60 of both sexes [8]. If parental cues are specific, transgenerational cues may induce tailored

61 changes in offspring phenotypes (e.g., altered metabolism vs increased antipredator behavior) 
62 that are adaptive for coping with specific environmental challenges (e.g., food instability vs.

63 predation).

64 To investigate the specificity of parental effects, we compared the intergenerational

65 effects of exposing fathers to a native predator (model sculpin Cottus asper) or to an artificial

66 stressor (nets). There is abundant evidence that parental exposure to predation risk can induce

67 offspring traits related to predator defense, such as protective "helmets" in Daphnia [9],

68 improved antipredator behavior in crickets [10], and altered activity and exploration under

69 high risk conditions in sticklebacks [11]. Artificial stimuli, such as nets, foot shocks or

70 confinement, are often used as proxy for a predator or to induce acute stress [12-14] and can

71 induce intergenerational effects $[15,16]$. Given that individuals have not encountered these

72 stimuli in their evolutionary history, it is unclear how individuals perceive them and if they

73 induce the same intergenerational response as a natural predator. We then examined offspring

74 of control fathers, sculpin-exposed fathers, and net-exposed fathers for a variety of

75 antipredator traits, including antipredator behaviors, acute (cortisol) stress, and body size. We

76 specifically tested the hypothesis that predator-induced paternal effects are specific, i.e. that

77 offspring of predator-exposed fathers differ from offspring of both control and net-exposed

78 fathers.

We paired this initial investigation of the specificity of paternal effects with a second

80 experiment to understand if stickleback behave differently in response to a net compared to a

81 model predator, which would suggest that they perceive nets and predators differently. For

82 instance, individuals might respond less strongly or quickly show a diminished response to

83 less threatening stimulus [17-19]. We sequentially exposed offspring of control, net-exposed,

84 and sculpin-exposed fathers to either a net, model sculpin, or model trout predator (another

85 stickleback predator that is not native to our population). This experiment also allowed us to

86 determine whether parental exposure to a stimulus primes offspring response to that stimulus, 
87 e.g. if offspring of sculpin-exposed fathers respond more strongly to sculpin while offspring

88 of net-exposed fathers respond more strongly to respond to a net.

\section{Method}

Housing conditions. Adult threespined sticklebacks were collected from Putah Creek,

92 a freshwater stream in Davis, California, in August 2017. This population has piscivorous

93 predators, including the prickly sculpin (Cottus asper). In October-November 2017, males

94 were transferred to individual 26.5L nesting tanks; once they built nests, males were

randomly assigned to a treatment in which they were either chased for 30 seconds every other

day for a twelve-day period ( 6 times total) with a net (10 by $12.5 \mathrm{~cm}$, green) or a clay model

experiments have shown that stickleback respond most strongly to visual cues of predation

99 [20] and model predators elicit anti-predator behaviors when brought into close proximity to

100 sticklebacks [21]. Males were not transferred between tanks using nets before the experiment

101 began to ensure that fathers were not habituated to the presence of a net; multiple nets of the same color and size were used to chase fathers.

The day after the last exposure, we removed the male, extracted his testes, and used

his sperm to fertilize eggs of a wild-caught, unexposed female. We placed fertilized eggs in a

105 cup with mesh bottom above a bubbler and monitored for mold before hatching. Stickleback

106 males produce sperm in the beginning of the breeding season; thus, paternal effects mediated

107 via sperm in this experiment are likely due to modifications to already mature sperm [22].

108 Because mothers and fathers did not interact with each other prior to fertilization or with their

109 offspring post-fertilization, we could isolate paternal effects mediated via sperm and

110 eliminate other potential sources of paternal effects, such as mate choice and differential

111 allocation mediated via parental care [23]. We generated 17 clutches: $n=6$ clutches of 
112 control fathers, $n=6$ clutches of net-exposed fathers, $n=5$ clutches of sculpin-exposed

113 fathers. In accordance with a previous study on sperm-mediated paternal effects in this

114 population [24], we found no detectable effect of paternal identity on any offspring traits

115 whose mean value was significantly altered by paternal treatment (unpublished analyses),

116 suggesting that genetic variation among clutches does not substantially alter these

117 intergenerational effects.

119 Part I: Transgenerational plasticity in response to an artificial stimuli (net) versus a 120 native predator (sculpin)

121 Behavioral assays. When offspring were 5 months old (mean days post-hatching:

$122145.9 \pm 0.64$ s.e.; February-April 2018), we measured activity and antipredator behavior

123 using methods described in Hellmann, Carlson [24] (5-13 offspring per clutch). The testing

124 arena was a circular arena $(150 \mathrm{~cm}$ diameter) divided into eight sections on the perimeter with

125 a middle circular section. We gently caught a fish from their home tank with a cup and

126 transferred it to an opaque container in the middle section. After a three minute acclimation

127 period, we removed the plug from the refuge, allowed the individual to emerge, and

128 measured the number of sections visited for three minutes after emergence as a proxy for

129 activity. If the fish did not emerge after 5 minutes, it was gently released from the refuge;

130 whether fish emerged naturally or were released did not alter activity (Welch's two sample t-

131 test: $\left.\mathrm{t}_{180.12}=-0.22, \mathrm{p}=0.83\right)$.

132 After the initial observation period, we simulated a sculpin predator attack by quickly

133 moving a clay predator sculpin toward the section of the pool with the experimental fish. We

134 measured two antipredator behaviors: whether this attack elicited evasive swimming behavior

135 (binomial) and how long the fish spent frozen after the simulated predator attack (continuous).

136 Once the fish resumed movement, we again measured the total number of sections visited for 
1373 minutes. We assayed $n=59$ offspring of control fathers $(n=30$ males, $n=29$ females $), n=$

13864 offspring of net-exposed fathers ( $n=33$ males, $n=31$ females $)$, and $n=60$ offspring of

139 sculpin-exposed fathers ( $\mathrm{n}=28$ males, $\mathrm{n}=32$ females $)$.

140 We left the fish in the assay arena for 15 minutes after the simulated predator attack in

141 order to measure peak circulating plasma cortisol in response to the predator attack [25]. We

142 then netted the fish from the arena and quickly weighed and measured it (standard length:

143 from the tip of the nose to the base of the caudal fin). We euthanized the fish in MS-222, cut

144 off the tail, and drew blood from the tail of the fish using a heparinized microhematocrit tube.

145 We centrifuged blood to separate the plasma (StatSpin CritSpin Microhemocrit centrifuge)

146 and immediately froze the plasma at $-80{ }^{\circ} \mathrm{C}$ for enzyme-linked immunosorbent assay (ELISA;

147 see supplementary material). We visually sexed offspring when possible, as many fish had

148 underdeveloped and non-reproductively mature gonads; we confirmed the accuracy of this

149 method and sexed the remainder of the fish using a genetic marker, per the methods of

150 Peichel, Ross [26]. Due to an insufficient amount of blood drawn from some offspring, our

151 final sample size analyzed was $n=38$ offspring of control fathers, $n=27$ offspring of net-

152 exposed fathers, and $n=31$ offspring from sculpin exposed fathers.

154 Statistical analysis. For all traits, we tested for differences in variance due to paternal

155 treatment using Fligner-Kileen tests. We computed the difference in activity before versus

156 after the attack (e.g. sections visited before - visited after the simulated predator attack). We

157 used linear mixed effects models to test predictors of activity differences and cortisol, and

158 generalized linear mixed models to test predictors of freezing behavior (negative binomial

159 distribution) and evasive swimming (binomial distribution) (R package lme4 [27]). The

160 models all included fixed effects of paternal treatment (control, net-exposed, sculpin-

161 exposed), offspring sex, and standard length; however, we used log-transformed tank density 
162 for the evasive swimming model instead because model comparisons showed tank density to

163 significantly improve model fit compared to standard length (standard length and density are

164 highly correlated; Spearman rank correlation, $\rho=-0.51, \mathrm{p}<0.001)$. We included a random

165 effect of clutch identity for all models, and observer identity for all behavioral models. We

166 removed 3 outliers from the cortisol dataset to normalize the residuals. We tested for

167 interactions between fixed effects and removed all non-statistically significant interactions.

168 For all models, we tested for differences among paternal treatment using Tukey's HSD

169 (package multcomp [28]).

171 Part II: The behavioral response of offspring to different stimuli

172 Open field assays. In April-May 2018, we ran the behavior assay on a different set of

173 offspring from the same clutches, using different stimuli to simulate a predator attack. Each

174 individual was isolated in a 10L tank $(\mathrm{L} 32 \times \mathrm{W} 21 \times \mathrm{H} 19 \mathrm{~cm})$ for at least $24 \mathrm{hrs}$ prior to the

175 first assay. Each individual was chased with three different stimuli in separate assays: 1) a net,

176 2) a model sculpin as above, and 3) a model trout (a stickleback predator that is not native to

177 the parents' population; $19.7 \mathrm{~cm}$ length). Assays were conducted in a random order, each 2-3

178 days apart; due to some experimental issues, not all fish received all three assays. After the

179 last assay, fish were euthanized with MS-222, weighed, measured, and sexed via visual

180 inspection of non-reproductively mature gonads. We conducted a total of $n=131$ assays: $n=$

18116 offspring of control fathers ( $n=16$ sculpin assays, $n=15$ net assays, $n=14$ trout assays), $n$

$182=16$ offspring of net-exposed fathers ( $\mathrm{n}=15$ sculpin assays, $\mathrm{n}=16$ net assays, $\mathrm{n}=12$ trout

183 assays), and $n=15$ offspring of sculpin-exposed fathers ( $n=15$ sculpin assays, $n=15$ net

184 assays, $\mathrm{n}=13$ trout assays). 
186 Statistical analysis. We reran the same behavioral models as above, with additional fixed

187 effects of assay treatment (net, sculpin, trout) and assay number (first, second, or third assay).

188 We included random effects of observer identity and fish ID nested with clutch. We tested for

189 interactions between fixed effects and removed all non-statistically significant interactions.

190 We removed one extremely low outlier from the activity dataset.

\section{Results}

193 Part I: Transgenerational plasticity in response to an artificial stimuli (net) versus a 194 native predator (sculpin)

195 We observed different inter-generational effects of chasing fathers with either an 196 artificial stimuli (net) or a native predator (sculpin).

197 Offspring behavior. Paternal treatment significantly altered offspring activity in

198 response to a simulated predator attack (Table 1): offspring of sculpin-exposed fathers

199 decreased activity more in response to the simulated predator attack compared to offspring of

200 control fathers (Tukey's HSD: $\mathrm{z}=1.93$, $\mathrm{p}=0.13$; Figure 1) while offspring of net-exposed

201 fathers did not decrease activity as much as offspring of control fathers $(\mathrm{z}=-1.15, \mathrm{p}=0.48$;

202 significant difference between offspring of net and sculpin-exposed fathers: $z=3.19, p=0.004$ ).

203 Further, although we did not detect an overall effect of paternal treatment on offspring

204 antipredator behavior (evasive swimming) (Table 1; Figure 2A), pairwise comparisons show

205 that offspring of net-exposed fathers were significantly less likely to perform evasive

206 swimming behavior compared to offspring of control fathers $(\mathrm{z}=-2.40, \mathrm{p}=0.04)$. Offspring of

207 sculpin-exposed fathers did not differ from offspring of control fathers $(\mathrm{z}=-1.45, \mathrm{p}=0.32)$.

208 Offspring freezing behavior was not detectably altered by paternal treatment (Table 1).

209 We did not detect an effect of offspring sex on activity or evasive swimming behavior,

210 although males spent less time frozen than females, and we did not detect an effect of 
211 offspring length on activity or freezing behavior (Table 1). Tank density tended to increase

212 the likelihood that offspring performed evasive swimming behaviors (Table 1). We did not

213 detect differences in variance on change in activity (Fligner-Killeen test: $\chi^{2}=1.42, p=0.49$ )

214 or freezing behavior $\left(\chi^{2}=0.53, \mathrm{p}=0.77\right)$ between paternal treatments.

217 exposure to the model sculpin relative to offspring of control fathers (Tukey's HSD: $\mathrm{z}=-2.50$,

$218 \mathrm{p}=0.03$, Table 1; Figure 3); we did not detect a difference between offspring of control and

219 sculpin-exposed fathers $(\mathrm{z}=-0.23, \mathrm{p}=0.97)$. Offspring body size interacted with paternal

220 treatment to influence cortisol (Table 1): large offspring of net-exposed fathers had higher

221 cortisol $\left(\mathrm{F}_{1,24.00}=8.08, \mathrm{p}=0.009\right)$, but this pattern was not apparent for offspring of control

222 fathers $\left(\mathrm{F}_{1,21.30}=0.04, \mathrm{p}=0.84\right)$ or sculpin-exposed fathers $\left(\mathrm{F}_{1,29}=0.01, \mathrm{p}=0.92\right)$. We did not

223 detect sex differences in cortisol (Table 1), and there was no evidence that paternal treatments

224 differed in variance $\left(\chi^{2}=0.26, \mathrm{p}=0.88\right)$.

Offspring body size. We did not detect paternal effects on mean offspring standard

227 length or mass (supplementary material). However, paternal treatments differed in the

228 variance of offspring standard length and mass (Fligner-Killeen test; mass: $\chi^{2}=14.50, p=$

229 0.002; SL: $\left.\chi^{2}=11.89, \mathrm{p}=0.008\right)$. Specifically, offspring of net-exposed fathers were more

230 variable in length and mass than offspring of sculpin-exposed fathers (SL: $\chi^{2}=5.17, p=0.02$;

231 mass: $\chi^{2}=12.85, \mathrm{p}<0.001$ ); offspring of net-exposed fathers were also more variable in

232 length than offspring of control fathers $\left(\chi^{2}=6.44, p=0.01\right)$. Neither of these differences in

233 variance could be attributed to higher within-clutch coefficients of variation (SL: $\mathrm{F}_{2,16}=0.18$,

$234 \mathrm{p}=0.68$; mass: $\left.\mathrm{F}_{2,16}=0.28, \mathrm{p}=0.84\right)$, suggesting that they are due to variation among fathers. 


\section{Part II: Offspring response to different stimuli}

237 We ran a second set of experiments in which each offspring was sequentially exposed

238 to an artificial stimulus (net), a native model sculpin predator, and a non-native model trout

239 predator. We observed different behavioral responses depending on which stimulus offspring

240 encountered (Table 2: evasive swimming). Specifically, sticklebacks were more likely to

241 perform evasive swimming behaviors when they encountered a sculpin compared to a net

$242(\mathrm{Z}=2.54, \mathrm{p}=0.03)$, but we did not detect a difference between stickleback's response to a

243 sculpin versus a trout $(\mathrm{Z}=1.06, \mathrm{p}=0.54$; Figure $2 \mathrm{~B}$, Table 2$)$.

244 Because individuals were repeatedly run through the behavioral assay, we could

245 examine how behavior changed with repeated testing in the behavioral assay. We detected

246 effects of repeated testing: regardless of the assay stimulus, offspring spent more time frozen

247 after the simulated attack in the first assay compared to later assays (Table 2). However, there

248 were more pronounced effects of repeated testing in response to some stimuli compared to

249 others (assay stimulus by assay number interaction for activity; Table 2; Figure 4). For

250 example, stickleback showed a greater reduction in activity after being chased by the net in

251 their first assay compared to later assays $\left(\mathrm{F}_{1,39}=13.33, \mathrm{p}<0.001\right)$. The same pattern was

252 evident for trout $\left(\mathrm{F}_{1,26.37}=16.23, \mathrm{p}<0.001\right)$. In contrast, when individuals were chased with a

253 sculpin, they showed similar reductions in activity in the first assay compared to later assays

$254\left(\mathrm{~F}_{1,39.97}=2.69, \mathrm{p}=0.11\right)$. This suggests that stickleback are less responsive to nets and non-

255 native trout predators following experience in the behavioral assay, but remain responsive to

256 native sculpin predators over time.

257 Because we measured the behavior of offspring of net-exposed versus sculpin-

258 exposed fathers, we looked for evidence that parental exposure to a given stimulus primes

259 offspring to respond to that stimulus (e.g., if offspring of net-exposed fathers are primed to

260 respond to nets). We did not detect evidence for paternal priming, as evidenced by non- 
261 statistically significant interactions between parental treatment and assay stimulus (Table 2).

262 The direction and magnitude of the paternal effects in Part I and Part II are similar (see

263 supplementary material); the failure to detect a significant effect of paternal treatment in Part

264 II likely reflects its smaller sample size.

\section{Discussion}

267 Here, we sought to investigate the specificity of transgenerational plasticity by

268 examining how offspring phenotypes varied when stickleback fathers were exposed to a

269 general, non-ecologically relevant stimulus (net) versus a native predator (sculpin). After a

270 simulated predatory sculpin attack, offspring of sculpin-exposed fathers showed a greater

271 reduction in activity compared to offspring of net-exposed fathers. On the other hand,

272 offspring of net-exposed fathers were less likely to perform antipredator behaviors (evasive

273 swimming) and had significantly lower circulating cortisol in response to the simulated

274 sculpin attack than offspring of control fathers, but these differences were not apparent for

275 offspring of sculpin-exposed fathers. This is consistent with previous findings that paternal

276 exposure to non-predation stress, transmitted to offspring via epigenetic changes to sperm,

277 reduces HPA stress axis responsivity and lowers offspring anxiety [29, 30]. Collectively,

278 these results demonstrate that paternal experience with different stimuli (net versus a predator)

279 alter offspring phenotypes in distinctive ways.

280 Consistent with other studies [10, 31, 32], offspring of predator-exposed fathers were

281 more responsive to simulated predation risk, in that they showed a greater reduction in

282 activity in response to risk compared to offspring of unexposed fathers. Given that prey often

283 decrease activity levels under high predation risk [33,34], this suggests that paternal

284 experience with a native predator heightens antipredator behavior. In contrast, paternal

285 exposure to a non-ecologically relevant stimulus (nets) actually decreased antipredator 
286 behavior in response to a simulated sculpin attack. It is possible that nets and predators elicit

287 different responses in fathers, which could explain why paternal effects in response to a net

288 versus a predator were different. Consistent with this explanation, we found that stickleback

289 behave differently toward nets and predators in Part II, which suggest that they perceive them

290 differently.

291 If different parental stimuli result in different offspring responses, then it is possible

292 that parents might be able to convey specific information about the stimulus that they

293 encountered. For example, offspring may be primed to respond to the same stimulus that their

294 father encountered (i.e., offspring of net-exposed fathers are more responsive to nets while

295 offspring of sculpin-exposed fathers are more response to sculpin). We did not detect

296 statistical evidence for this possibility; instead, we found that stickleback were generally

297 more responsive to a native model sculpin predator compared to a net or non-native model

298 trout. Namely, offspring were more likely to perform antipredator behaviors when they

299 encountered a sculpin compared to a net; further, across the trials, offspring became less

300 responsive to nets and non-native trout predators, but not to native sculpin predators. This is

301 consistent with previous findings that individuals adjust the intensity of antipredator behavior

302 after assessing the nature and overall threat of predation risk and that less threatening stimuli

303 elicit an attenuated response over time [17-19].

304 Given that the animals used in Part II were previously predator-naïve, our results

305 suggest that sticklebacks have innate predator recognition of native predators, even in the

306 absence of olfactory or chemical predation cues. A number of fishes show innate predator

307 recognition [35-37]. Although there is some evidence that learned predator avoidance is

308 important in sticklebacks [38, 39], innate predator recognition may also occur: a previous

309 study in sticklebacks also found that overhead fright response to birds is independent of

310 predation experience [40]. This innate recognition of sculpin may arise from predator 
311 coloration or functional morphology (e.g., shape) [41, 42]. Indeed, our results do suggest that

312 predator shape or coloration may be important for generalizing across different predators:

313 stickleback that encountered a trout showed intermediate levels of antipredator (evasive

314 swimming) behavior compared to stickleback who encountered a sculpin or net. This

315 suggests that sticklebacks may be able to partially generalize predation risk to a non-native

316 predator.

317 In addition to changes in mean offspring traits, we also found higher variance in

318 standard length and body mass in offspring of net-exposed fathers, but not in offspring of

319 sculpin-exposed fathers. Given that we found no differences in within-clutch coefficients of

320 variation between treatment groups, our data suggest that higher variance cannot be attributed

321 to 'bet-hedging', where each father produces offspring with a wide range of different

322 phenotypes [43]. Instead, these shifts in variance likely result from differences among fathers

323 in how they responded to the net treatment. This is consistent with previous results in

324 sticklebacks that found that fathers who encountered a novel predator showed a more variable

325 changes in paternal care behaviors relative to fathers who encountered a native predator, who

326 showed consistent directional changes in behavior [44].

327 In conclusion, here we show that prefertilization paternal exposure to both an artificial

328 stimulus (net) and a native predator induce changes in offspring phenotypes; however, each

329 stimulus induced different changes in offspring phenotypes, demonstrating that sperm-

330 mediated paternal effects can be highly specific to the stimulus fathers encounter. Our study

331 suggests that, while non-ecologically relevant stimuli elicit effects in intergenerational studies,

332 caution should be used when trying to extrapolate those findings to understand

333 intergenerational effects in response to evolved stimuli such as predators. Further, these

334 results are consistent with the idea that different parental stimuli do not activate a core,

335 conserved pathway, although there may be common offspring traits, such as dispersal [4] or 
336 body size [45-47], that are altered by cues indicating low quality or risky environments.

337 Instead, our results are consistent with the hypothesis that that different sensory neurons or

338 neuroanatomical pathways are activated in response to each stimulus and somehow alter

339 sperm content (e.g., small RNAs [48-50]) in distinct ways, similar to the ways in which

340 paternal exposure to different odors can induce specific aversions in offspring [15]. Further

341 investigation into the underlying mechanisms, as well as the fitness consequences of each

342 exposure with respect to survival against predators, would be exciting avenues for future

343 work. 


\section{Acknowledgements and funding}

346 Thank you to the Bell lab for comments on previous versions of this manuscript and

347 to Ryan Earley for help with the hormone assays. This work was supported by the National

348 Institutes of Health award number 2R01GM082937-06A1 to AMB and National Institutes of

349 Health NRSA fellowship F32GM121033 to JKH. The authors have no conflicts of interest.

\section{Author contributions}

352 In Part I, EC and CZ generated offspring, conducted behavioral assays and offspring

353 sexing, and processed the cortisol samples. JD and RS conducted behavioral assays for Part

354 II. JKH collected cortisol samples and conducted the statistical analyses. EC, CZ, and JKH

355 designed the studies and drafted the manuscript. AMB provided space and equipment for the

356 experiments, financial support, helped with the statistical analyses, and edited the manuscript

357 with JKH. All authors gave final approval for publication and agree to be held accountable

358 for the work performed therein. 
359 Table 1: We used general linear mixed models to understand how paternal treatment altered

360 offspring activity before versus after the simulated predator attack (higher values indicate a

361 greater reduction in activity), freezing behavior, evasive swimming, and offspring cortisol

362 responses at 5 months. All individuals underwent one open field assay, in which they were

363 chased with a model predator sculpin.

364

365

\begin{tabular}{|c|c|c|c|}
\hline & \multicolumn{3}{|c|}{ Change in activity $(n=183)$} \\
\hline & $F$ & $d . f$ & $\mathrm{p}$ \\
\hline Paternal treatment & 5.13 & $2,61.36$ & 0.009 \\
\hline Offspring sex & 0.35 & $1,177.20$ & 0.55 \\
\hline \multirow[t]{3}{*}{ Offspring standard length } & 0.51 & $1,114.6$ & 0.48 \\
\hline & \multicolumn{3}{|c|}{ Freezing behavior $(n=183)$} \\
\hline & $F$ & $d . f$ & $\mathrm{p}$ \\
\hline Paternal treatment & 0.43 & 2,175 & 0.61 \\
\hline Offspring sex & 5.88 & 1,175 & 0.02 \\
\hline \multirow[t]{3}{*}{ Offspring standard length } & 0.49 & 1,175 & 0.48 \\
\hline & \multicolumn{3}{|c|}{ Evasive swimming $(n=183)$} \\
\hline & $F$ & d.f & $\mathrm{p}$ \\
\hline Paternal treatment & 1.77 & 2,176 & 0.17 \\
\hline Offspring sex & 0.35 & 1,176 & 0.55 \\
\hline \multirow[t]{3}{*}{ Tank density } & 3.03 & 1,176 & 0.08 \\
\hline & \multicolumn{3}{|c|}{ Cortisol $(n=96)$} \\
\hline & $F$ & $d . f$ & $\mathrm{p}$ \\
\hline Paternal treatment & 3.31 & $2,75.33$ & 0.04 \\
\hline Offspring sex & 0.77 & $1,88.92$ & 0.38 \\
\hline Offspring standard length & 3.03 & $1,81.35$ & 0.09 \\
\hline Treatment * length & 0.16 & $2,77.80$ & 0.05 \\
\hline
\end{tabular}


366 Table 2: We used general linear mixed models to understand offspring's response to

367 different stimuli ( $\mathrm{n}=131$ assays). We tested the effects of paternal treatment (control, net-

368 exposed, and sculpin-exposed) and assay stimulus (sculpin, net, trout) on offspring activity

369 behavior (higher values indicate a greater reduction in activity after the predator attack),

370 freezing behavior, and evasive swimming (binomial). Individuals underwent three open field

371 assays, and were chased with each of the three assay stimuli in a randomized order.

372

373

374

\begin{tabular}{|l|c|c|c|}
\hline \multirow{2}{*}{} & \multicolumn{3}{|c|}{ Change in activity } \\
\cline { 2 - 4 } & $F$ & $d . f$ & $\mathrm{p}$ \\
\hline Paternal treatment & 0.70 & $2,7.84$ & 0.52 \\
\hline Assay stimulus & 3.90 & $2,116.54$ & $\mathbf{0 . 0 2}$ \\
\hline Assay number & 28.59 & $1,82.34$ & $<\mathbf{0 . 0 0 1}$ \\
\hline Offspring sex & 0.16 & $1,41.71$ & 0.69 \\
\hline Offspring standard length & 0.81 & $1,16.63$ & 0.38 \\
\hline Assay stimulus * assay number & 3.30 & $2,115.10$ & $\mathbf{0 . 0 4}$ \\
\hline \multirow{4}{*}{} & \multicolumn{3}{|c|}{ Freezing behavior } \\
\cline { 2 - 4 } & $F$ & $d . f$ & $\mathrm{p}$ \\
\hline Paternal treatment & 1.13 & 2,118 & 0.33 \\
\hline Assay stimulus & 0.56 & 2,118 & 0.57 \\
\hline Offspring sex & 0.09 & 1,118 & 0.76 \\
\hline Assay number & 12.39 & 1,118 & $<\mathbf{0 . 0 0 1}$ \\
\hline Offspring standard length & 0.70 & 1,118 & 0.40 \\
\hline \multirow{3}{*}{ Evasive swimming } \\
\hline Paternal treatment & $F$ & $d . f$ & $\mathrm{p}$ \\
\hline Assay stimulus & 2.53 & 2,120 & 0.08 \\
\hline Offspring sex & 4.08 & 2,120 & $\mathbf{0 . 0 2}$ \\
\hline Assay number & 0.12 & 1,120 & 0.72 \\
\hline Tank density & 0.10 & 1,120 & 0.75 \\
\hline
\end{tabular}




\section{Figure Legends}

380 Figure 1: Relative to offspring of net-exposed fathers (blue), offspring of sculpin-exposed

381 fathers (yellow) had a significantly greater reduction in activity in response to a simulated

382 model sculpin attack in the open field assay (mean \pm s.e.).

384 Figure 2: A) In Part I, paternal treatment (control, net-exposed, sculpin-exposed)

385 significantly altered evasive swimming behavior of offspring in response to a simulated

386 model sculpin attack in the open field assay. Shown are the proportion of individuals who

387 performed this behavior (binomial response). B) In Part II, assay stimulus (net, sculpin

388 predator, trout predator) significantly influenced whether offspring displayed evasive

389 swimming behavior in response to a simulated attack in the open field assay. Letters indicate

390 significant differences among treatment groups (Tukey’s HSD).

391

392 Figure 3: Relative to offspring of control fathers (grey), offspring of net-exposed fathers

393 (blue) had significantly lower circulating cortisol (ng/ml) 15 minutes after a simulated model

394 sculpin attack in the open field assay (interquartile range with median). These patterns were

395 not present for offspring of sculpin-exposed fathers (yellow). Grey circles represent

396 individual data points.

398 Figure 4: In Part II, offspring who encountered a non-native trout predator or a net show a

399 smaller decrease in activity in response to the simulated predator attack in later assays

400 compared to the first assay (interquartile range with median). However, this trend was not

401 present for offspring who were exposed to a native sculpin predator in the assay. Grey circles

402 represent individual data points. See Supplementary Figure 1 for plot of raw data. 


\section{References}

405 [1] Jablonka, E., Oborny, B., Molnar, I., Kisdi, E., Hofbauer, J. \& Czaran, T. 1995 The

406 adaptive advantage of phenotypic memory in changing environments. Philosophical

407 Transactions of the Royal Society B: Biological Sciences 350, 133-141.

408 (doi:10.1098/rstb.1995.0147).

409 [2] Bell, A.M. \& Hellmann, J.K. 2019 An integrative framework for understanding the

410 mechanisms and multigenerational consequences of transgenerational plasticity. Annual

411 Review of Ecology, Evolution and Systematics 50, 97-118. (doi:10.1146/annurev-ecolsys-

412 110218-024613).

413 [3] Herman, J. \& Sultan, S. 2011 Adaptive transgenerational plasticity in plants: case studies, 414 mechanisms, and implications for natural populations. Frontiers in Plant Science 2, 102.

415 (doi:10.3389/fpls.2011.00102).

416 [4] Potticary, A.L. \& Duckworth, R.A. in press Multiple environmental stressors induce an

417 adaptive maternal effect. American Naturalist.

418 [5] Oliva-Paterna, F.J., Miñnano, P.A. \& Torralva, M. 2003 Habitat quality affects the 419 condition of Barbus sclateri in Mediterranean semi-arid streams. Environmental Biology of

420 Fishes 67, 13-22. (doi:10.1023/A:1024481928161).

421 [6] Navarro-Castilla, Á. \& Barja, I. 2019 Stressful living in lower-quality habitats? Body

422 mass, feeding behavior and physiological stress levels in wild wood mouse populations.

423 Integrative Zoology 14, 114-126. (doi:10.1111/1749-4877.12351).

424 [7] Cīrule, D., Krama, T., Krams, R., Elferts, D., Kaasik, A., Rantala, M.J., Mierauskas, P.,

425 Luoto, S. \& Krams, I.A. 2017 Habitat quality affects stress responses and survival in a bird

426 wintering under extremely low ambient temperatures. The Science of Nature 104, 99.

427 (doi:10.1007/s00114-017-1519-8).

428 [8] He, N., Kong, Q.-Q., Wang, J.-Z., Ning, S.-F., Miao, Y.-L., Yuan, H.-J., Gong, S., Cui,

429 X.-Z., Li, C.-Y. \& Tan, J.-H. 2016 Parental life events cause behavioral difference among

430 offspring: Adult pre-gestational restraint stress reduces anxiety across generations. Scientific

431 Reports 6, 39497. (doi:10.1038/srep39497).

432 [9] Agrawal, A.A., Laforsch, C. \& Tollrian, R. 1999 Transgenerational induction of defences

433 in animals and plants. Nature 401, 60-63. (doi:10.1038/43425).

434 [10] Storm, J. \& Lima, S. 2010 Mothers forewarn offspring about predators: a

435 transgenerational maternal effect on behavior. The American Naturalist 175, 382-390.

436 (doi:10.1086/650443).

437 [11] Hellmann, J.K., Bukhari, S.A., Deno, J. \& Bell, A.M. in review Sex-specific

438 transgenerational plasticity I: Maternal and paternal effects on sons and daughters. Journal of

439 Animal Ecology. (doi:bioRxiv: 10.1101/763862).

440 [12] Ramsay, J.M., Feist, G.W., Varga, Z.M., Westerfield, M., Kent, M.L. \& Schreck, C.B.

4412009 Whole-body cortisol response of zebrafish to acute net handling stress. Aquaculture 297,

442 157-162. (doi:10.1016/j.aquaculture.2009.08.035).

443 [13] Mileva, V.R., Fitzpatrick, J.L., Marsh-Rollo, S., Gilmour, K.M., Wood, C.M. \&

444 Balshine, S. 2009 The stress response of the highly social African cichlid Neolamprologus

445 pulcher. Physiol Biochem Zool 82, 720-729. (doi:10.1086/605937).

446 [14] Bali, A. \& Jaggi, A.S. 2015 Electric foot shock stress: a useful tool in neuropsychiatric

447 studies. Reviews in the Neurosciences 26, 655-677. (doi:10.1515/revneuro-2015-0015).

448 [15] Dias, B.G. \& Ressler, K.J. 2014 Parental olfactory experience influences behavior and

449 neural structure in subsequent generations. Nature Neuroscience 17, 89-96.

450 (doi:10.1038/nn.3594). 
451 [16] Schneider, M.L. \& Coe, C.L. 1993 Repeated social stress during pregnancy impairs

452 neuromotor development of the primate infant. Journal of Developmental and Behavioral

453 Pediatrics 14, 81-87. (doi:10.1097/00004703-199304000-00002).

454 [17] Królikowska, N., Szymkowiak, J., Laidlaw, R.A. \& Kuczyński, L. 2016 Threat-sensitive

455 anti-predator defence in precocial wader, the northern lapwing Vanellus vanellus. acta

456 ethologica 19, 163-171. (doi:10.1007/s10211-016-0236-1).

457 [18] Schneider, N.A. \& Griesser, M. 2012 Incubating females use dynamic risk assessment to

458 evaluate the risk posed by different predators. Behavioral Ecology 24, 47-52.

459 (doi:10.1093/beheco/ars134).

460 [19] Helfman, G.S. 1989 Threat-sensitive predator avoidance in damselfish-trumpetfish

461 interactions. Behavioral Ecology and Sociobiology 24, 47-58.

462 [20] Landeira-Dabarca, A., Näslund, J., Johnsson, J.I. \& Álvarez, M. 2019 Cue recognition

463 and behavioural responses in the three-spined stickleback (Gasterosteus aculeatus) under risk

464 of fish predation. acta ethologica 22, 209-221. (doi:10.1007/s10211-019-00324-8).

465 [21] Näslund, J., Pettersson, L. \& Johnsson, J.I. 2016 Behavioural reactions of three-spined

466 sticklebacks to simulated risk of predation-Effects of predator distance and movement.

467 FACETS 1, 55-66. (doi:10.1139/facets-2015-0015).

468 [22] Borg, B. 1982 Seasonal effects of photoperiod and temperature on spermatogenesis and

469 male secondary sexual characters in the three-spined stickleback, Gasterosteus aculeatus L.

470 Canadian Journal of Zoology 60, 3377-3386. (doi:10.1139/z82-427).

471 [23] McGhee, K.E., Feng, S., Leasure, S. \& Bell, A.M. 2015 A female's past experience with

472

473

474

475

476

477

478

479

480

481

482

483

484

485

486

487

488

489

490

491 predators affects male courtship and the care her offspring will receive from their father.

Proceedings of the Royal Society B 282. (doi:10.1098/rspb.2015.1840).

[24] Hellmann, J.K., Carlson, E.R. \& Bell, A.M. in review Sex-specific transgenerational plasticity II: Grandpaternal effects are lineage- and sex-specific in threespined sticklebacks. Journal of Animal Ecology. (doi:bioRxiv: 10.1101/796995).

[25] Mommer, B.C. \& Bell, A.M. 2013 A test of maternal programming of offspring stress response to predation risk in threespine sticklebacks. Physiology and Behavior 122, 222-227. (doi:10.1016/j.physbeh.2013.04.004).

[26] Peichel, C.L., Ross, J.A., Matson, C.K., Dickson, M., Grimwood, J., Schmutz, J., Myers, R.M., Mori, S., Schluter, D. \& Kingsley, D.M. 2004 The master sex-determination locus in threespine sticklebacks is on a nascent Y chromosome. Current Biology 14, 1416-1424. (doi:10.1016/j.cub.2004.08.030).

[27] Bates, D., Mächler, M., Bolker, B. \& Walker, S. 2015 Fitting linear mixed-effects models using lme4. Journal of Statistical Software; Vol 1, Issue 1 (2015).

[28] Hothorn, T., Bretz, F. \& Westfall, P. 2008 Simultaneous inference in general parametric models. Biometrical Journal 50, 346-363.

[29] Rodgers, A.B., Morgan, C.P., Bronson, S.L., Revello, S. \& Bale, T.L. 2013 Paternal stress exposure alters sperm microRNA content and reprograms offspring HPA stress axis regulation. Journal of Neuroscience 33, 9003-9012. (doi:10.1523/JNEUROSCI.091413.2013).

492 [30] Short, A.K., Fennell, K.A., Perreau, V.M., Fox, A., O’Bryan, M.K., Kim, J.H., Bredy, 493 T.W., Pang, T.Y. \& Hannan, A.J. 2016 Elevated paternal glucocorticoid exposure alters the 494 small noncoding RNA profile in sperm and modifies anxiety and depressive phenotypes in 495 the offspring. Translational Psychiatry 6, e837. (doi:10.1038/tp.2016.109).

496 [31] Stein, L.R. \& Bell, A.M. 2014 Paternal programming in sticklebacks. Animal Behaviour 497 95, 165-171. (doi:10.1016/j.anbehav.2014.07.010).

498 [32] Donelan, S.C. \& Trussell, G.C. 2015 Parental effects enhance risk tolerance and 499 performance in offspring. Ecology 96, 2049-2055. (doi:10.1890/14-1773.1). 
500 [33] Relyea, R.A. 2004 Fine-tuned phenotypes; tadpole plasticity under 16 combinations of 501 predators and competitors. Ecology 85, 172-179. (doi:10.1890/03-0169).

502 [34] Lima, S.L. 1998 Stress and decision making under the risk of predation: recent

503 developments from behavioral, reproductive, and ecological perspectives. In Advances in the

504 Study of Behavior (eds. A.P. Møller, M. Milinski \& P.J.B. Slater), pp. 215-290, Academic

505 Press.

506 [35] Dixson, D.L., Munday, P.L. \& Jones, G.P. 2010 Ocean acidification disrupts the innate

507

508

509

510

511 (doi:10.1371/journal.pone.0076061). ability of fish to detect predator olfactory cues. Ecology Letters 13, 68-75.

(doi:10.1111/j.1461-0248.2009.01400.x).

[36] Oulton, L.J., Haviland, V. \& Brown, C. 2013 Predator recognition in rainbowfish,

512 [37] Hirvonen, H., Ranta, E., Piironen, J., Laurila, A. \& Peuhkuri, N. 2000 Behavioural

513 responses of naive Arctic charr young to chemical cues from salmonid and non-salmonid fish.

514 Oikos 88, 191-199. (doi:10.1034/j.1600-0706.2000.880121.x).

515 [38] Golub, Justin L. 2013 Embryonic learning in threespine stickleback (Gasterosteus

516 aculeatus) [Doctoral], Clark University.

517 [39] Chivers, D.P., Brown, G.E. \& Smith, R.J.F. 1995 Acquired recognition of chemical

518 stimuli from pike, Esox lucius, by Brook Sticklebacks, Culaea inconstans (Osteichthyes,

519 Gasterosteidae). Ethology 99, 234-242. (doi:10.1111/j.1439-0310.1995.tb00897.x).

520 [40] Giles, N. 1984 Development of the overhead fright response in wild and predator-naive three-spined sticklebacks, Gasterosteus aculeatus L. Animal Behaviour 32, 276-279. (doi:10.1016/S0003-3472(84)80347-4).

523 [41] Hettyey, A., RÖLli, F., ThÜRlimann, N., ZÜRcher, A.-C. \& Van Buskirk, J. 2012

524 Visual cues contribute to predator detection in anuran larvae. Biological Journal of the

525 Linnean Society 106, 820-827. (doi:10.1111/j.1095-8312.2012.01923.x).

526 [42] Fischer, S., Oberhummer, E., Cunha-Saraiva, F., Gerber, N. \& Taborsky, B. 2017 Smell

527 or vision? The use of different sensory modalities in predator discrimination. Behavioral

528 Ecology and Sociobiology 71, 143. (doi:10.1007/s00265-017-2371-8).

529

530

531

532

533

534 [43] Crean, A.J. \& Marshall, D.J. 2009 Coping with environmental uncertainty: dynamic bet hedging as a maternal effect. Philosophical Transactions of the Royal Society B: Biological Sciences 364, 1087.

[44] Stein, L.R. \& Bell, A.M. 2019 The role of variation and plasticity in parental care during the adaptive radiation of three-spine sticklebacks. Evolution 73, 1037-1044. (doi:10.1111/evo.13711).

[45] Caton, J.S., Crouse, M.S., Reynolds, L.P., Neville, T.L., Dahlen, C.R., Ward, A.K. \&

538 [46] Marshall, D.J. 2008 Transgenerational plasticity in the sea: context-dependent maternal 539 effects across the life history. Ecology 89, 418-427. (doi:10.1890/07-0449.1).

540 [47] Brunton, P.J. 2013 Effects of maternal exposure to social stress during pregnancy: 541 consequences for mother and offspring. Reproduction 146, R175-R189. (doi:10.1530/REP542 13-0258).

543 [48] Gapp, K., Jawaid, A., Sarkies, P., Bohacek, J., Pelczar, P., Prados, J., Farinelli, L., Miska, 544 E. \& Mansuy, I.M. 2014 Implication of sperm RNAs in transgenerational inheritance of the 545 effects of early trauma in mice. Nature Neuroscience 17, 667-669. (doi:10.1038/nn.3695).

546 [49] Immler, S. 2018 The sperm factor: paternal impact beyond genes. Heredity 121, 239-247. 547 (doi:10.1038/s41437-018-0111-0). 
bioRxiv preprint doi: https://doi.org/10.1101/2020.06.04.135152; this version posted June 5, 2020. The copyright holder for this preprint (which was not certified by peer review) is the author/funder, who has granted bioRxiv a license to display the preprint in perpetuity. It is made available under aCC-BY-ND 4.0 International license.

548 [50] Rodgers, A.B., Morgan, C.P., Leu, N.A. \& Bale, T.L. 2015 Transgenerational epigenetic 549 programming via sperm microRNA recapitulates effects of paternal stress. Proceedings of the 550 National Academy of Sciences 112, 13699-13704. (doi:10.1073/pnas.1508347112).

551

552 


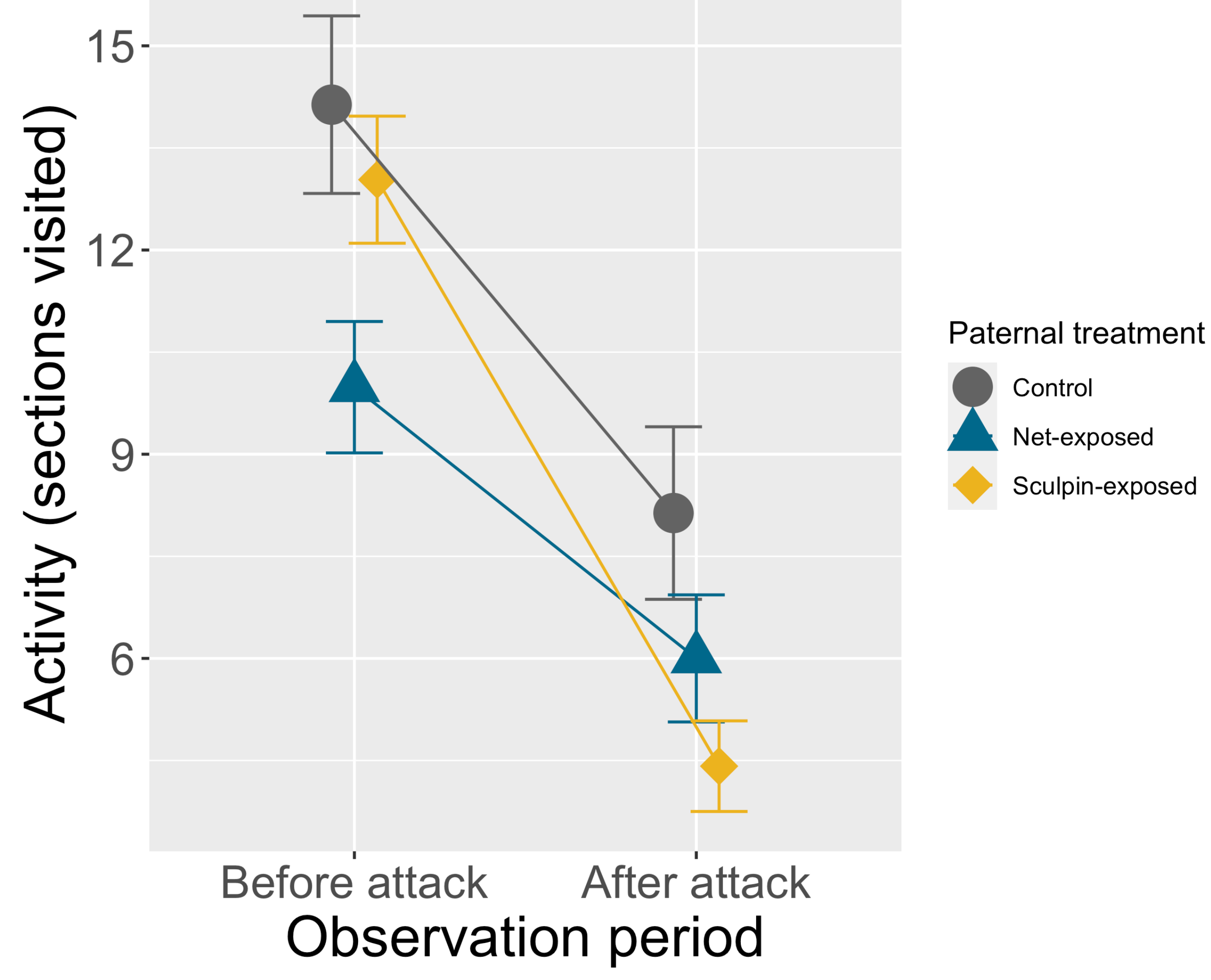




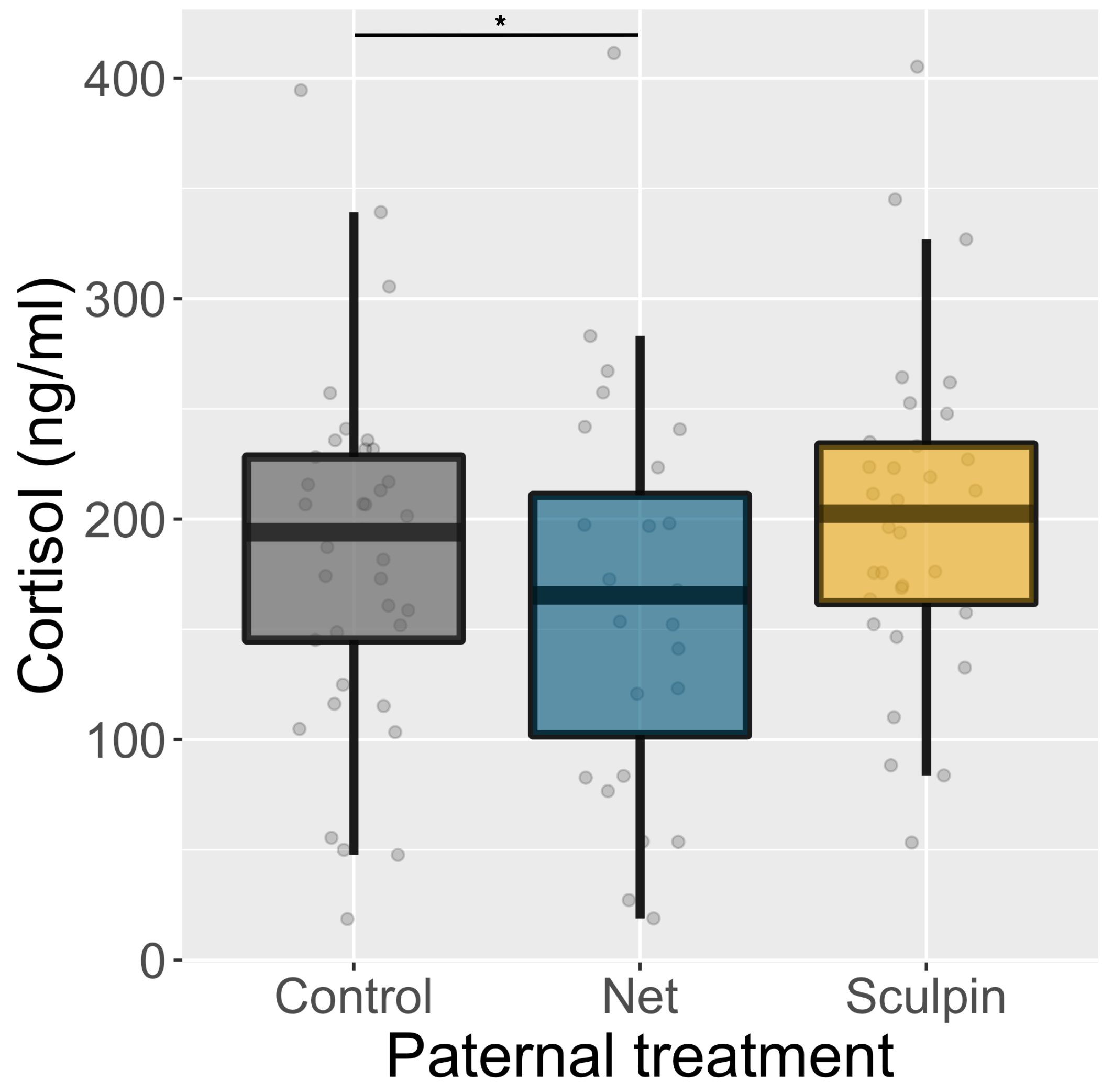


